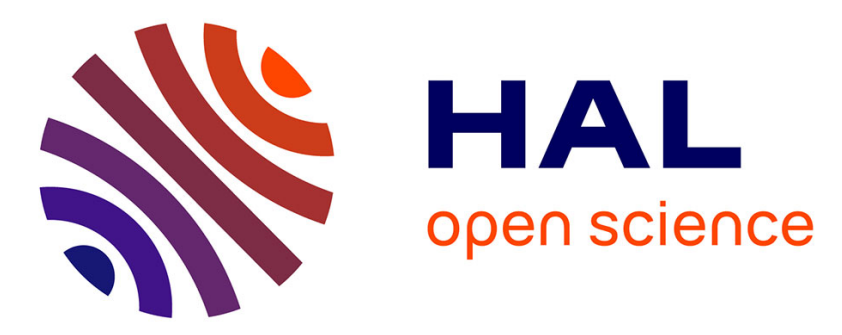

\title{
AlN/GaN/Sapphire heterostructure for high-temperature packageless acoustic wave devices
}

F. Bartoli, Thierry Aubert, Mohammed Moutaouekkil, Jérémy Streque, Philippe Pigeat, S. Zhgoon, Abdelkrim Talbi, Sami Hage-Ali, Hamid M 'Jahed, Omar Elmazria

\section{To cite this version:}

F. Bartoli, Thierry Aubert, Mohammed Moutaouekkil, Jérémy Streque, Philippe Pigeat, et al.. AlN/GaN/Sapphire heterostructure for high-temperature packageless acoustic wave devices. Sensors and Actuators A: Physical , 2018, 283, pp.9-16. 10.1016/j.sna.2018.08.011 . hal-01868387

\section{HAL Id: hal-01868387 \\ https://hal.univ-lorraine.fr/hal-01868387}

Submitted on 5 Sep 2018

HAL is a multi-disciplinary open access archive for the deposit and dissemination of scientific research documents, whether they are published or not. The documents may come from teaching and research institutions in France or abroad, or from public or private research centers.
L'archive ouverte pluridisciplinaire HAL, est destinée au dépôt et à la diffusion de documents scientifiques de niveau recherche, publiés ou non, émanant des établissements d'enseignement et de recherche français ou étrangers, des laboratoires publics ou privés. 


\title{
AlN/GaN/Sapphire heterostructure for high-temperature packageless acoustic wave devices
}

\author{
F. Bartoli ${ }^{1,2,3}$, T. Aubert ${ }^{1,2}$, M. Moutaouekkil ${ }^{3,6}$, J. Streque $^{3}$, P. Pigeat ${ }^{3}$, S. Zhgoon ${ }^{4}$, A. \\ Talbi $^{5}$, S. Hage-Ali ${ }^{3}$, H. M'Jahed ${ }^{3}$, O. Elmazria ${ }^{3}$
}

\footnotetext{
${ }^{1}$ LMOPS EA 4423, Université de Lorraine 57070 Metz, France

${ }^{2}$ LMOPS EA 4423, CentraleSupélec, Université Paris-Saclay

${ }^{3}$ Institut Jean Lamour, UMR 7198, Université de Lorraine-CNRS, 54000 Nancy, France

${ }^{4}$ National Research University “MPEI”, 14, Krasnokazarmennaya, 121351, Moscow Russia

5 Joint International Laboratory LIA LICS, Univ. Lille, CNRS, Centrale Lille, ISEN, Univ. Valenciennes, UMR 8520 - IEMN, 59651 Villeneuve d'Ascq, France

${ }^{6}$ LPMR, Faculté des Sciences, Université Mohammed I, Oujda, Morocco
}

Abstract - Surface acoustic waves (SAW) technology is very promising to achieve wireless sensors able to operate in high temperature environments up to possibly $1000^{\circ} \mathrm{C}$. However, there is currently a bottleneck related to the packaging of such sensors. The current high-temperature packaging solutions can withstand $600^{\circ} \mathrm{C}$ at most. This limitation could be overtaken by the development of packageless devices, based on the waveguiding layer acoustic waves (WLAW) principle. In such devices, the acoustic wave is confined inside an inner layer and is then isolated from undesired surface perturbations like dust deposition.

In this paper, we investigate the performance of an AIN/IDT/GaN/Sapphire WLAW device used as a temperature sensor able to operate up to $500^{\circ} \mathrm{C}$. After validating a room-temperature GaN material constant set with basic SAW measurements performed on IDT/GaN/Sapphire structure, the AIN/IDT/GaN/Sapphire device is 
simulated to determine the optimal relative thicknesses of $\mathrm{AIN}$ and GaN films in order to obtain a good wave confinement. Based on these calculations, an experimental WLAW device is performed and electrically characterized. The full wave confinement is experimentally confirmed by the lamination of an acoustic absorber on top of the device: no change in the scattering parameters was observed. The WLAW device is then electrically characterized between the ambient temperature and $500^{\circ} \mathrm{C}$. A temperature coefficient of frequency (TCF) value of $-34.6 \mathrm{ppm} /{ }^{\circ} \mathrm{C}$ is obtained, demonstrating the potential of the WLAW AIN/IDT/GaN/Sapphire structure as a packageless temperature sensor. Finally, the theoretical TCF of the AIN/IDT/GaN/Sapphire structure was numerically calculated by changing the material constants of AIN, GaN and Sapphire according to the temperature coefficients available in the literature. The theoretical and experimental data were found in good accordance.

Keywords — SAW; Packageless Sensor; TCF; WLAW; High-temperature

\section{INTRODUCTION}

Surface acoustic wave (SAW) devices are massively used as RF filters in mobile communication devices. As SAW devices are very sensitive to environmental parameters, they are also intensively studied for sensor applications [1]. Moreover, SAW devices being passive components, they can be remotely interrogated without embedded electronics or on-board power source. This last property makes this technology particularly suitable for high temperature applications. Currently, conventional wireless sensors are based on silicon integrated electronics, which are limited to $200^{\circ} \mathrm{C}$. Many studies have been conducted in the last two decades to identify piezoelectric materials and metals for interdigital transducers (IDT) able to operate at high temperatures. Conventional SAW substrates like quartz, congruent lithium niobate or lithium tantalate are not suitable for temperatures above $400-450^{\circ} \mathrm{C}$ [2]. Actually, very few piezoelectric materials can withstand high temperatures beyond this 
threshold. So far, the most advanced candidate is langasite $\left(\mathrm{La}_{3} \mathrm{Ga}_{5} \mathrm{SiO}_{14} ; \mathrm{LGS}\right)$ whose surface is stable up to $1000^{\circ} \mathrm{C}$ for weeks under air atmosphere [3-4]. Moreover, 4-inches LGS wafers of different orientations are commercially available and reliable high-temperature elastic constants of LGS have been recently published, allowing the prediction of the frequencytemperature law of a given LGS-based SAW device in a large temperature range [5]. Still, the upper temperature range of wireless interrogation of LGS-based SAW devices is $600-700^{\circ} \mathrm{C}$ [6-7] because the electrical resistivity of this material drops in the range of $10^{5} \Omega . \mathrm{cm}$ at $700^{\circ} \mathrm{C}$ [8]. In this context, the most promising candidate to achieve wireless SAW sensors able to operate above $700^{\circ} \mathrm{C}$ is $\mathrm{AlN} /$ sapphire bilayer structure, which shows an electrical resistivity five orders of magnitude higher than that of LGS [9], and could be possibly used up to $900^{\circ} \mathrm{C}$ in the air [10-12]. However, the development of a high-temperature packaging solution constitutes a technological bottleneck, the most advanced solutions being limited to $600^{\circ} \mathrm{C}[13]$. Indeed, SAW devices must be packaged in order to protect the thin film electrodes from accidental scratches and isolate the acoustic wave from surface perturbations such as dust deposition. Several studies have shown the possibility to achieve packageless acoustic wave devices, using the waveguiding layer acoustic waves (WLAW) technology [14-15]. WLAW devices are made from a tri-layer structure, in which the inner layer shows a significantly lower acoustic velocity and thus lower acoustic impedance than both surrounding materials (Fig.1). Consequently, the acoustic wave is trapped inside the inner layer, and thus is insensitive to surface perturbations but still sensitive to bulk influences like temperature or strain modifications. In practice, at least one of the layers has to be a piezoelectric material in order to generate the acoustic waves. One additional advantage of packageless WLAW sensors is that the electrodes are buried and thus protected from physical and chemical alterations [16]. The extreme miniaturization of the device, achieved by removing the package, is also interesting for industrial perspectives. 
III-Nitride materials as well as sapphire are well known for their robustness regarding harsh environments and their high electrical resistivity [17-18]. Moreover, sapphire and AlN are very stiff materials which show high acoustic velocity: the velocity of Rayleigh waves is around $5600 \mathrm{~m} / \mathrm{s}$ for both c-oriented AlN and sapphire. In the case of gallium nitride (GaN), this velocity is significantly lower, being equal to $3700 \mathrm{~m} / \mathrm{s}$ [19]. Consequently, we consider in this paper the AlN/IDT/GaN/Sapphire structure as a promising WLAW structure for hightemperature applications.

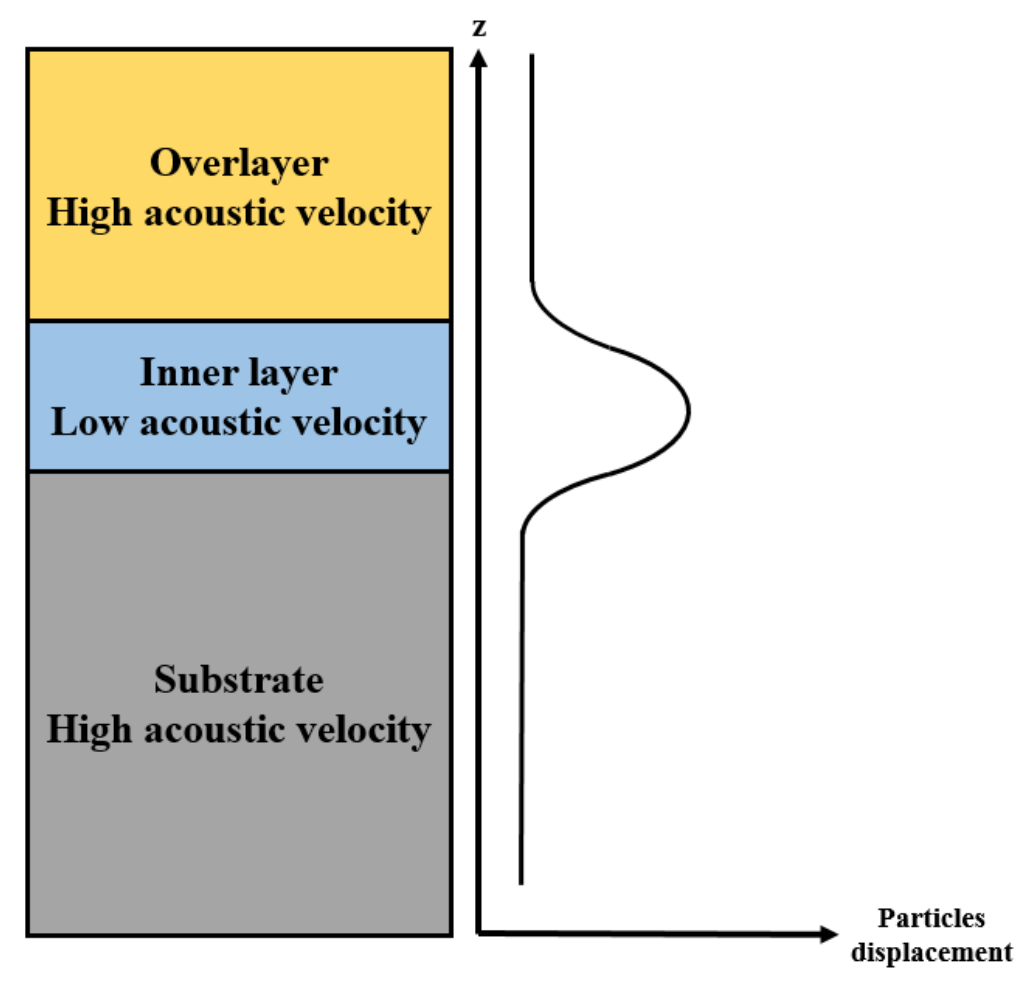

Fig. 1: Schematized WLAW structure.

In order to develop fully operational WLAW sensors based on this layered structure, it is necessary to simulate the device behavior using reliable physical constant sets in a large temperature range for the three constitutive materials. Thus, the robustness of some constant sets available in the literature is checked by comparing experimental and calculated results of basic AlN/Sapphire and GaN/Sapphire SAW devices. The most reliable sets are then used to determine numerically the possibility to generate WLAW in the AlN/GaN/Sapphire structure at room temperature, and to optimize the films' respective thicknesses. Based on these 
calculations, an AlN/GaN/Sapphire WLAW device is fabricated and electrically characterized between room temperature and $500^{\circ} \mathrm{C}$.

\section{METHODS}

\subsection{Model description and selection of material constants sets}

The numerical results including dispersion and S11 curves are calculated by a 2D-FEM modeling (software Comsol Multiphysics ${ }^{\circledR}$ ), using the general partial differential equations interface, and applying the Bloch periodic boundary conditions to the unit cells (Fig. 2) along the X-axis and considering one period of SAW structure as shown in fig. 5. The used model describes an infinite aperture IDT with infinite number of fingers. Thus, the electromechanical coupling coefficient $\mathrm{K}^{2}$, and the wave velocity are calculated using the admittance of the unit cell. Sapphire is a well-known crystal for which reliable room temperature-data, as well as associated first-order temperature coefficients, are available [20]. Besides, a room-temperature constants set of AlN/Sapphire bilayer structure had already been validated in previous studies [21]. In the present work, the GaN/Sapphire bilayer structure is firstly considered to find reliable room temperature GaN material constant sets. To do so, calculated velocity dispersion curves are compared with the experimental one obtained from the characterization of GaN/Sapphire SAW devices (see next section). Then, the full AlN/IDT/GaN/Sapphire WLAW structure is simulated, using aluminum as metal for IDTs, and using the separately validated constants sets of the four considered materials. Finally, different first-order temperature coefficient sets are tested for GaN and AlN by comparing calculated and experimental temperature coefficient of frequency (TCF) dispersion curves for GaN/Sapphire and AlN/Sapphire SAW bilayer structures. The experimental data come from previous studies in the case of AlN/Sapphire [22, $23,24]$.

Table I summarizes the room temperature physical constants considered for sapphire, $\mathrm{Al}$ and $\mathrm{AlN}$, and the three different sets tested for GaN. Table II gives the various sets of first- 
order temperature coefficients of elastic constants $\mathrm{C}_{\mathrm{ij}}(\mathrm{T})$, and thermal expansion coefficients $\alpha_{\mathrm{ii}}$ considered in the calculations.

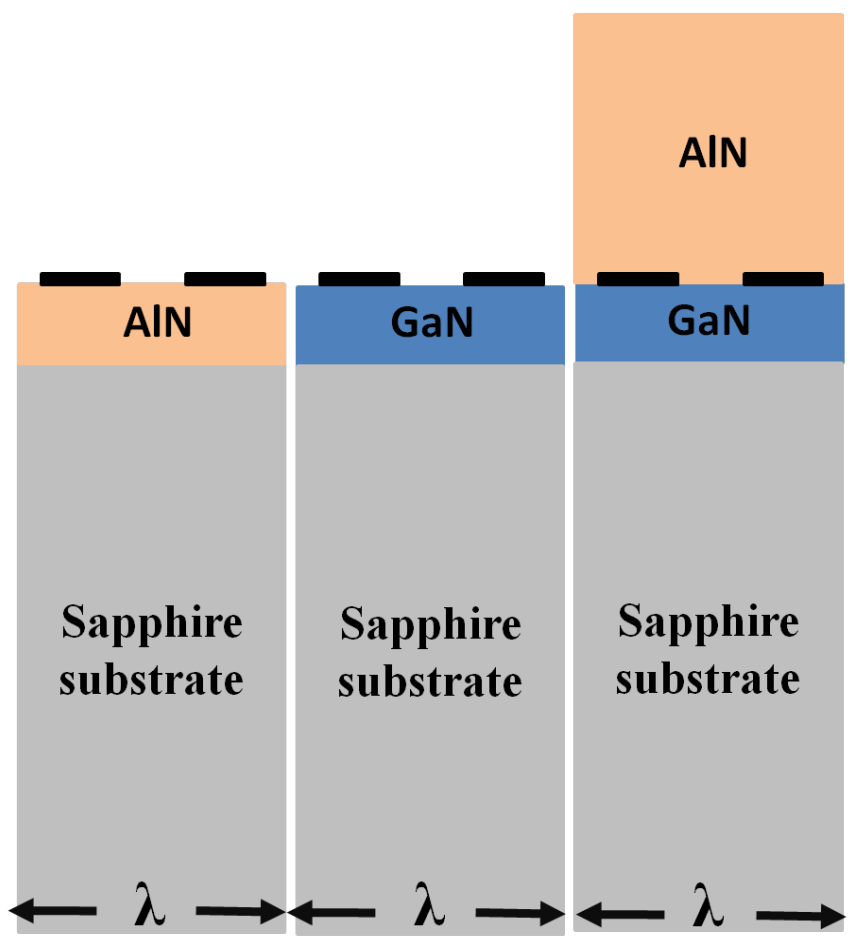

Fig. 2: Schematic 2D representation of the unit cell of the investigated structures: Al/AIN/Sapphire, Al/GaN/Sapphire and AlN/Al/GaN/Sapphire.

Tab. I: Room-temperature physical constants of Al, AIN, GaN and Sapphire (Tref $=\mathbf{2 5}^{\circ} \mathrm{C}$ ).

\begin{tabular}{|c|c|c|c|c|c|c|c|c|c|c|c|c|c|c|c|}
\hline Material & \multicolumn{7}{|c|}{ Elastic Stiffness (GPa) } & \multicolumn{3}{|c|}{$\begin{array}{c}\text { Piezoelectric } \\
\text { constants }\left(\mathrm{C} / \mathbf{m}^{2}\right)\end{array}$} & \multicolumn{3}{|c|}{$\begin{array}{l}\text { Dielectric constants } \\
\left(10^{-11} \mathrm{~F} / \mathrm{m}\right)\end{array}$} & \multirow{2}{*}{$\begin{array}{c}\begin{array}{c}\text { Density } \\
\left(\mathrm{kg} / \mathrm{m}^{3}\right)\end{array} \\
\rho\end{array}$} & \multirow[t]{2}{*}{ Ref } \\
\hline Constant & $\mathbf{C}_{11}$ & $\mathbf{C}_{12}$ & $\mathbf{C}_{13}$ & $\mathbf{C}_{14}$ & $\mathbf{C}_{33}$ & $\mathrm{C}_{44}$ & $\mathrm{C}_{66}$ & $\mathbf{e}_{15}$ & $\mathbf{e}_{31}$ & $\mathbf{e}_{33}$ & $\varepsilon_{11}$ & $\varepsilon_{22}$ & $\varepsilon 33$ & & \\
\hline Al & 107.3 & 60.8 & $\mathrm{X}$ & $\mathrm{X}$ & $\mathrm{X}$ & 28.3 & $\mathrm{X}$ & $\mathrm{X}$ & $\mathrm{X}$ & $\mathrm{X}$ & $\mathrm{X}$ & $\mathrm{X}$ & $\mathrm{X}$ & 2702 & [25] \\
\hline Sapphire & 497 & 164 & 111 & -23.5 & 498 & 147 & $\mathrm{X}$ & $\mathrm{X}$ & $\mathrm{X}$ & $\mathrm{X}$ & 8.28 & 8.28 & 0.12 & 3980 & [20] \\
\hline AIN & 345 & 125 & 120 & $\mathrm{X}$ & 395 & 118 & 110 & -0.48 & -0.58 & 1.55 & 8 & 8 & 9.5 & 3260 & [26] \\
\hline GaN & 350 & 140 & 104 & $\mathrm{X}$ & 376 & 101 & 115 & 0.5 & -0.32 & 0.63 & 8.9 & 8.9 & 8.9 & 6150 & [27] \\
\hline GaN & 390 & 145 & 106 & $\mathrm{X}$ & 398 & 105 & 123 & 0.5 & -0.32 & 0.65 & 8.9 & 8.9 & 8.9 & 6150 & [27] \\
\hline GaN & 370 & 145 & 110 & $X$ & 390 & 90 & 113 & 0.5 & -0.32 & 0.65 & 8.9 & 8.9 & 8.9 & 6150 & [27] \\
\hline
\end{tabular}


Tab. II: First-order temperature coefficient of elastic constants and expansion coefficients of the AIN, GaN and Sapphire.

\begin{tabular}{|c|c|c|c|c|c|c|c|c|c|c|c|}
\hline Material & \multicolumn{7}{|c|}{ Temperature coefficients $\left(\mathbf{p p m} /{ }^{\circ} \mathrm{C}\right)$} & \multicolumn{3}{|c|}{$\begin{array}{l}\text { Thermal expansion } \\
\text { coefficients }\left(10^{-6} /{ }^{\circ} \mathrm{C}\right)\end{array}$} & \multirow[t]{2}{*}{ Ref } \\
\hline Constant & $C_{11}(T)$ & $\mathrm{C}_{12}(\mathrm{~T})$ & $\mathrm{C}_{13}(\mathrm{~T})$ & $\mathrm{C}_{14}(\mathrm{~T})$ & $\mathrm{C}_{33}(\mathrm{~T})$ & $\mathrm{C}_{44}(\mathrm{~T})$ & $\mathrm{C}_{66}(\mathrm{~T})$ & $\alpha_{11}(T)$ & $\alpha_{22}(T)$ & ${ }_{a .33}(\mathrm{~T})$ & \\
\hline Sapphire & -75 & 40 & -80 & -70 & -85 & -180 & $\mathrm{X}$ & 7.28 & 7.28 & 8.11 & {$[20]$} \\
\hline AlN & 80 & 180 & 160 & $\mathrm{X}$ & 100 & 50 & $\mathrm{X}$ & 5.27 & 5.27 & 4.15 & {$[21]$} \\
\hline AlN & -28 & -35 & -40 & $\mathrm{X}$ & -30 & -11 & $\mathrm{X}$ & 5.27 & 5.27 & 4.15 & {$[28]$} \\
\hline AIN & -37 & -1.8 & -1.8 & $X$ & -65 & -50 & -57 & 5.27 & 5.27 & 4.15 & {$[26]$} \\
\hline GaN & 47.1 & 94.7 & 94.7 & $\mathrm{X}$ & 52.5 & 9.9 & 16.7 & 5.2 & 5.2 & 3.95 & $\begin{array}{l}{[27]-} \\
\text { LDA }\end{array}$ \\
\hline GaN & 49.5 & 97.9 & 97.9 & $\mathrm{X}$ & 52.9 & 12.7 & 19.8 & 5.2 & 5.2 & 3.95 & $\begin{array}{l}{[27]-} \\
\text { GGA }\end{array}$ \\
\hline GaN & -15 & -16.9 & -33.7 & $\mathrm{X}$ & -23.6 & -6.9 & -6.9 & 4.45 & 4.45 & 3.03 & [29] \\
\hline GaN & -42.5 & -45.9 & -53 & $\mathrm{X}$ & -59.4 & -15.8 & -15.8 & 4.45 & 4.45 & 3.03 & [28] \\
\hline
\end{tabular}

The reference [27] contains multiple constants sets for the GaN material. One of them is calculated by local-density-approximation (LDA), and the other by the generalized-gradientapproximation (GGA).

\subsection{Experimental}

Commercial GaN/Sapphire bilayer structures were purchase from Kyma Technologies, Rayleigh, NC, USA. The $2 \mu \mathrm{m}$-thick, c-oriented, non-intentionally doped GaN films were hetero-epitaxially grown by MOCVD on c-cut sapphire substrates. $200 \mathrm{~nm}$-thick aluminum films were deposited onto the GaN/Sapphire structures and patterned by conventional contact ultraviolet (UV) photolithography and wet etching to achieve SAW synchronous single-port resonators. The Al IDTs were made of 100 finger pairs, with a metallization ratio of $50 \%$ and 
an aperture of $40 \cdot \lambda$. Different wavelengths comprised between 5 and $24 \mu \mathrm{m}$ were used. The resonators were equipped with 200 reflectors on each side of the IDT. The propagation path of the acoustic waves was along the X-direction of the sapphire substrates.

Finally, AlN/Al/GaN/Sapphire WLAW structures were fabricated. $12 \mu \mathrm{m}$-thick AlN film was grown onto the previously described $\mathrm{Al} / \mathrm{GaN} /$ Sapphire $\mathrm{SAW}$ structures with a wavelength of $5 \mu \mathrm{m}$, using reactive magnetron sputtering. The AlN thickness was measured by in-situ reflectometry and its microstructure was determined by X-ray diffraction (XRD) $\theta-2 \theta$ measurements (Bruker D8 Advance CuK $\alpha 1$ ). The IDTs contacts were protected by a tantalum hard mask during the AlN deposition in order to keep a subsequent electrical access to the device.

Both SAW and WLAW devices were electrically characterized up to $500^{\circ} \mathrm{C}$ in air atmosphere using a network analyzer (PNA 5230a, Agilent Technologies Inc., Santa Clara, CA) and an RF probe station (S-1160, Signatone Corp., Gilroy, CA) equipped with a S-1060 series Signatone thermal probing system and water-cooled RF probes (Z-Probe, Süss Microtech AG, Garching, Germany) so that it can withstand temperatures up to $600^{\circ} \mathrm{C}$. Before all measurements, the RF setup was conventionally calibrated in order to obtain reliable measurements.

In order to verify experimentally the confinement of the wave in the inner layer of the WLAW device, an elastomeric material was placed on the surface of the top AlN film (Fig. 3). Whereas a SAW should suffer from strong viscous losses in the soft medium placed at the surface of the structure, a WLAW should be insensitive to it [30]. To make this test as selective as possible, a particularly soft elastomer (Solaris ${ }^{\circledR}$, Smooth-on, USA, EYoung $\left.=172 \mathrm{kPa}\right)$ has been chosen. The results of this test are shown on figure 10 . 


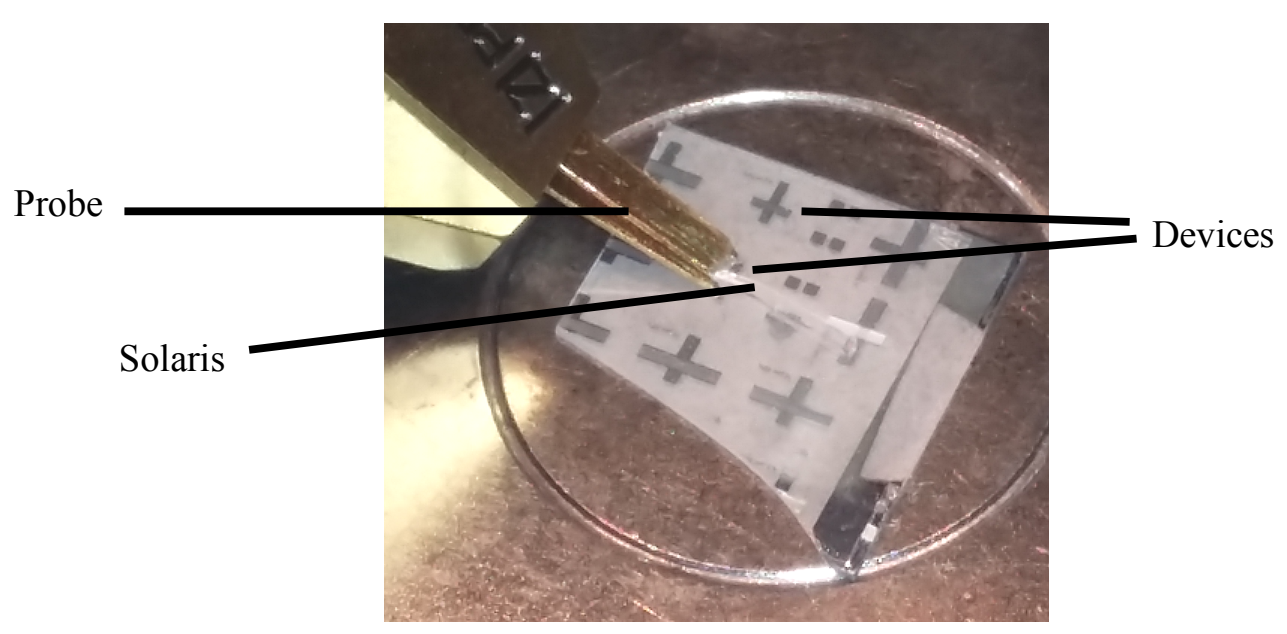

Fig. 3: Measurements of the WLAW scattering parameters, during the Solaris elastomer test.

\section{RESULTS AND DISCUSSION}

\subsection{Room Temperature results}

The comparison between the calculated Rayleigh wave dispersion curves and the ones obtained from the experimental characterization of GaN/Sapphire SAW devices is shown in Fig. 4. A good agreement is obtained in a large range of GaN relative thicknesses, with the roomtemperature constant calculated by the local-density-approximation (LDA). 


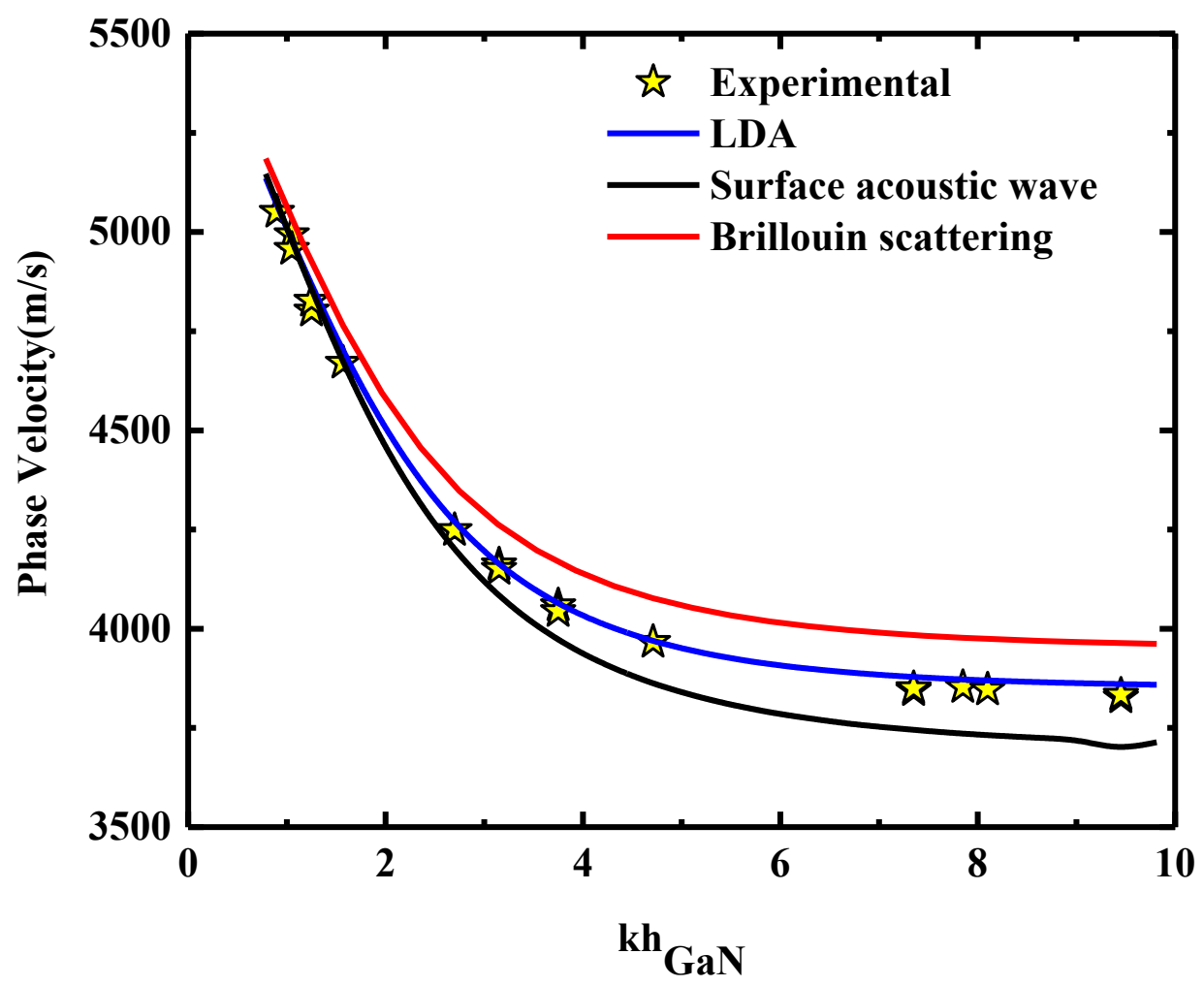

Fig. 4: Comparison between experimental (yellow stars) and calculated (lines) phase velocity dispersion curves of Rayleigh waves propagating in GaN/Sapphire bilayer structure, made by using the material GaN constants taken from references [27].

To simulate the whole $\mathrm{AlN} / \mathrm{Al} / \mathrm{GaN} / \mathrm{Sapphire}$ structure we consider the sets from references [20], [21] and [27] respectively for AlN, Sapphire and GaN. As the trapping of the acoustic wave inside the inner layer becomes more efficient when the respective thicknesses of the surrounding layers increase, a thick AIN overlayer of $20 \mu \mathrm{m}$ was firstly considered to ensure the hypothetical confinement of the wave. Simulations show that the expected WLAW mode can propagate in the structure under certain conditions (Fig. 5). 


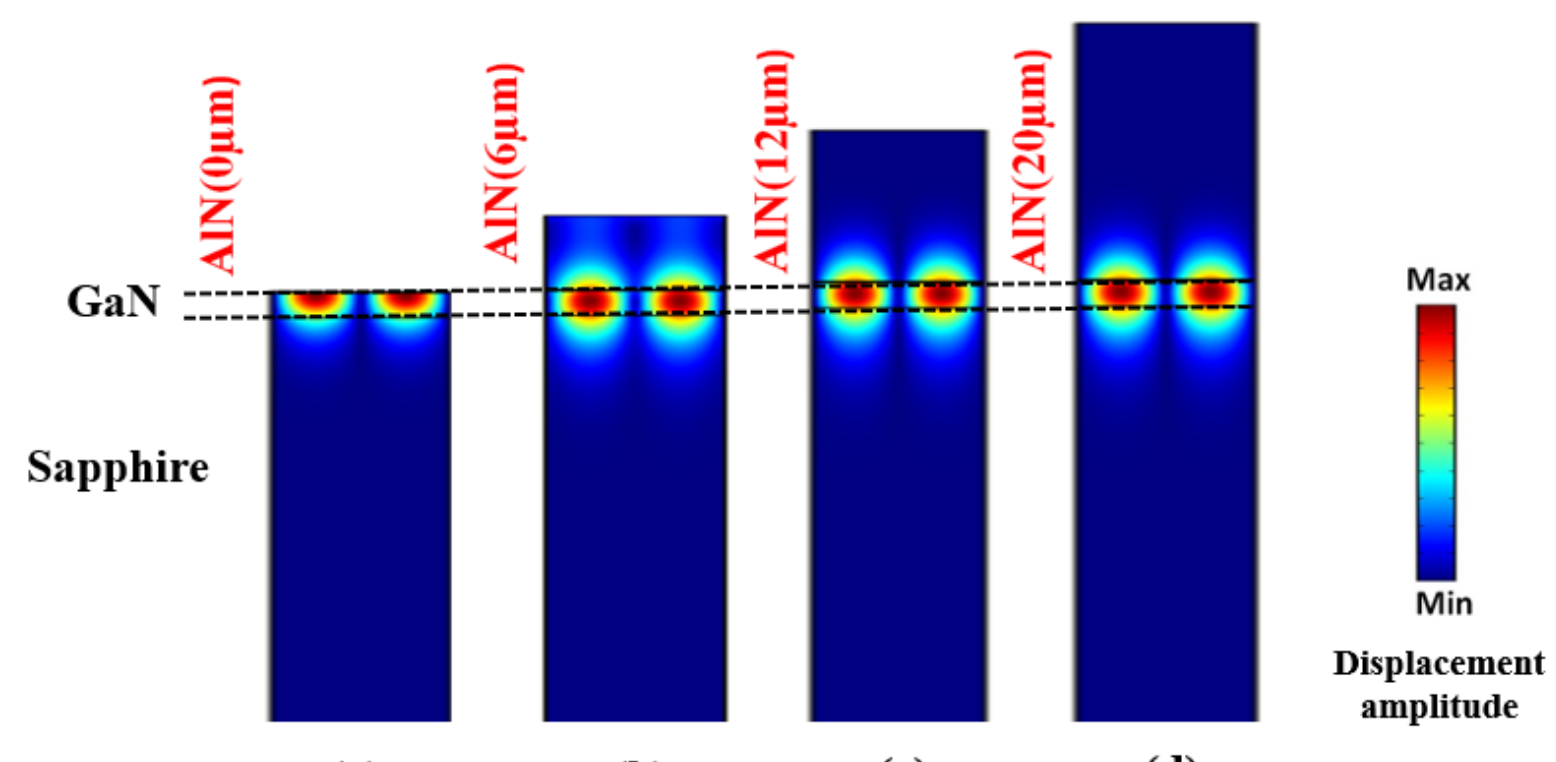

(a)

(b)

(c)

(d)

Fig. 5: Total displacement in the AIN/Al/GaN/Sapphire structure with different AIN thicknesses: (a) $0 \mu \mathrm{m}$, (b) $6 \mu \mathrm{m}$, (c) $12 \mu \mathrm{m}$ and (d) $20 \mu \mathrm{m}$.

The phase velocity dispersion curve of the AlN/Al/GaN/Sapphire structure was calculated for fixed AlN thickness $(20 \mu \mathrm{m})$; figure 6 shows the phase velocity and $\mathrm{K}^{2}$ dispersion curves. Both experimental and theoretical values of $\mathrm{K}^{2}$ was determined using from admittance versus frequency curves considering resonance $\left(f_{r}\right)$ and antiresonance $\left(f_{a}\right)$ frequencies and using the following formula [31-32]:

$$
K^{2}(\%)=2 \times \frac{f_{a}-f_{r}}{f_{a}} \times 100
$$

One can observe that the maximum value of $\mathrm{K}^{2}$, namely $0.21 \%$, is reached when the relative thickness of the GaN layer kh $\mathrm{GaN}_{\mathrm{Ga}}$ is in the range between 2.6 and 2.9, with a WLAW velocity between 5100 and $4900 \mathrm{~m} / \mathrm{s}$ respectively. Taking into account that the actual GaN thickness of the samples is $2 \mu \mathrm{m}$, obtaining the maximum $\mathrm{K}^{2}$ requires a wavelength close to $5 \mu \mathrm{m}$.

The figure 7 shows the particles displacement and their position inside the three-layer structure following the thickness of the AlN thin film. As we can see in this figure, the particles displacement at the surface of the device decreases when the AlN thickness increases. For subsequent calculations, the GaN thickness was set to $2 \mu \mathrm{m}$, the wavelength to $5 \mu \mathrm{m}$, and the 
AlN overlayer thickness was steadily reduced in order to find the minimum value allowing the propagation of the WLAW, i.e. an acoustic wave trapped inside the GaN inner layer. We used as numerical criterion for the wave confinement, a surface displacement below $1 \%$ of the wave's maximum displacement. Using this criterion, the minimum thickness of AlN for our structure was found to be equal to $12 \mu \mathrm{m}$. Then, it was decided to grow a $12 \mu \mathrm{m}$-thick AlN film onto the $\mathrm{Al} / \mathrm{GaN} / \mathrm{Sapphire} \mathrm{SAW}$ devices, where The AlN thin film have been grown using a sputtering power of $200 \mathrm{~W}$. The gas used was composed with only N2 at 5 mTorr pressure, with a substrate-target distance of $5 \mathrm{~cm}$. The substrate was not subject to any heating. The growth rate obtained with those parameters was of $100 \mathrm{~nm}$ in $12 \mathrm{~min}$.

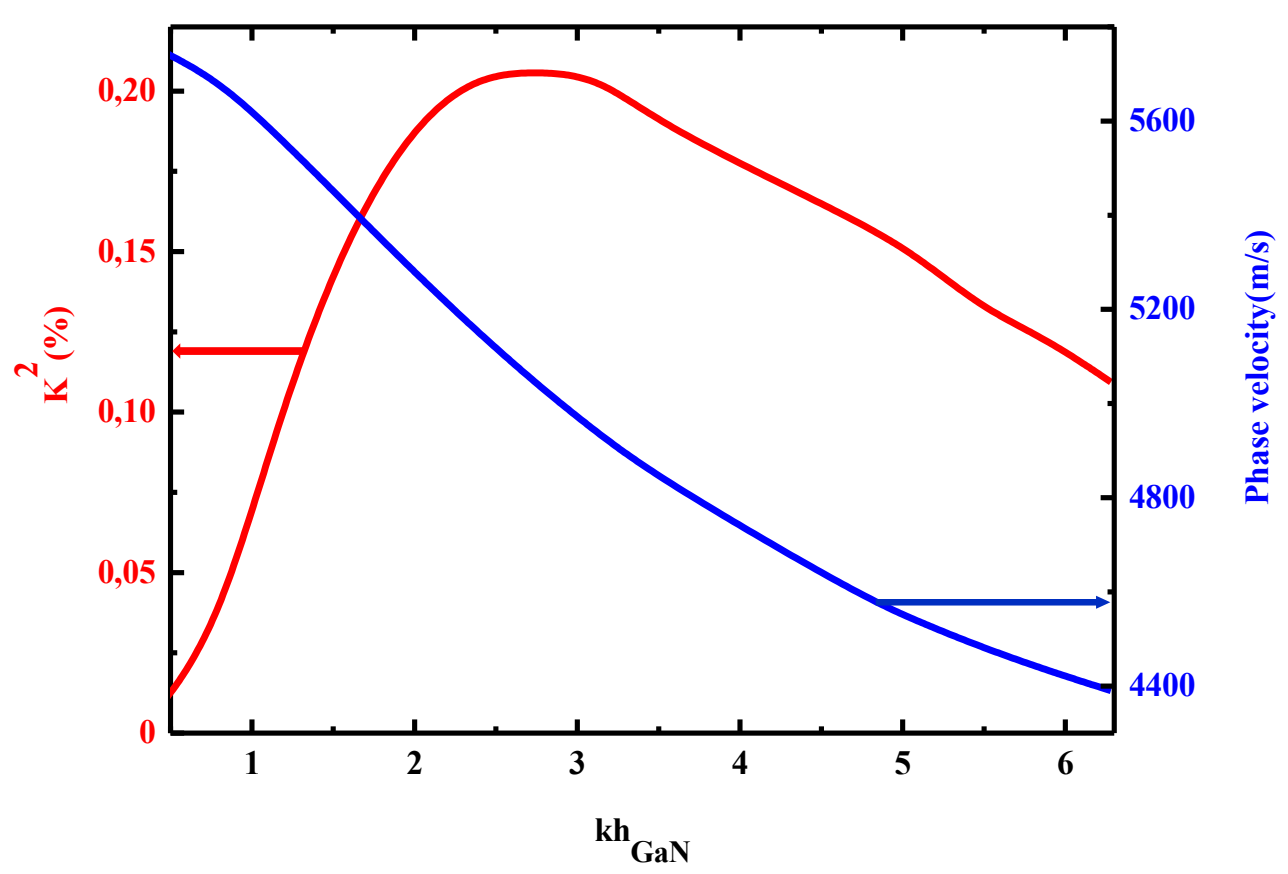

Fig. 6: Phase velocity and $K^{2}$ dispersion curves of the WLAW mode in $\operatorname{AlN}(20 \mu \mathrm{m}) / \mathbf{A l} / \mathbf{G a N} /$ Sapphire structures. 


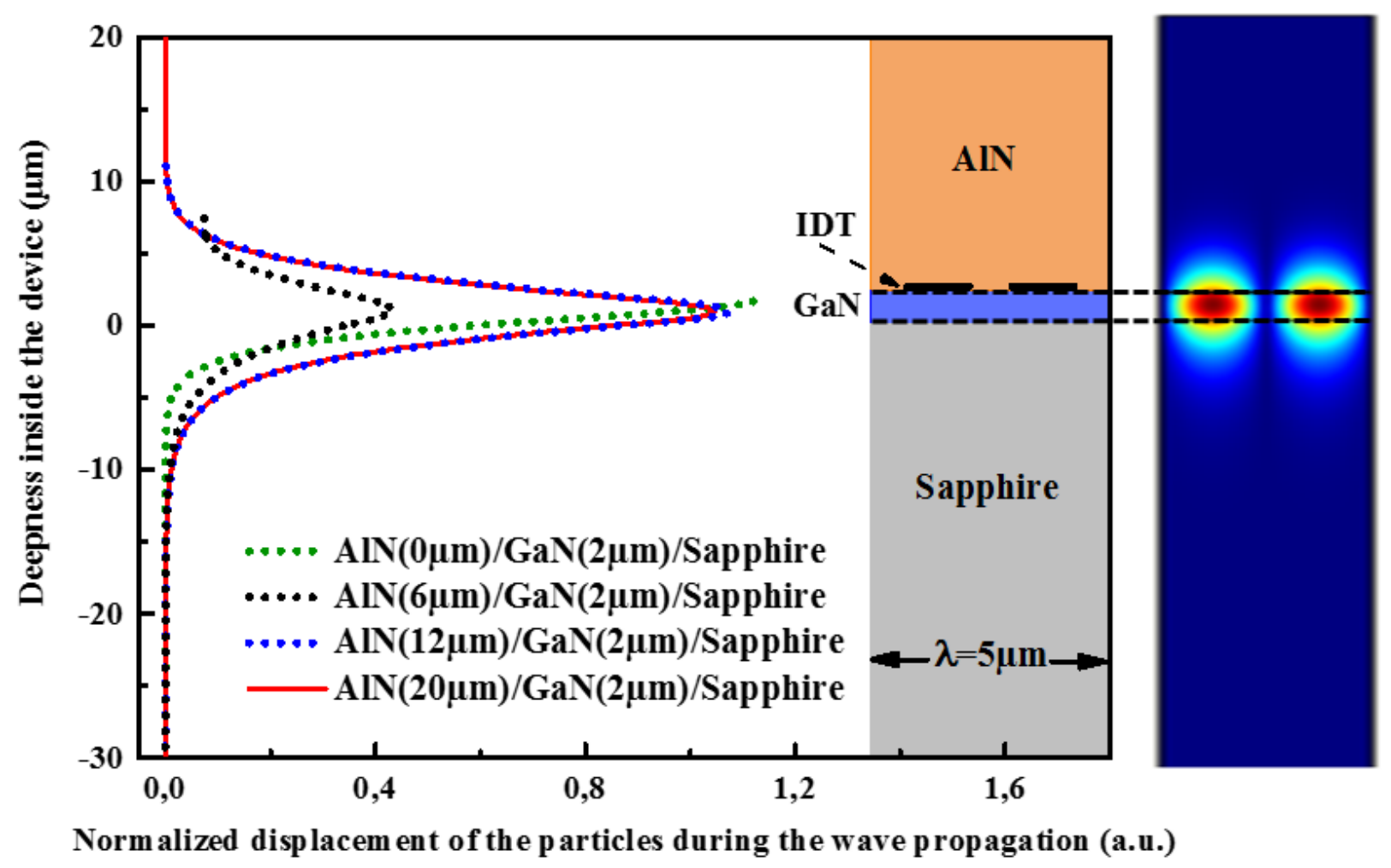

Fig. 7: Intensity of the particles vertical displacement related to the WLAW propagating in the AIN/Al/GaN/Sapphire structure, versus vertical coordiante. Four different AIN thicknesses were considered in the simulations.

Figure 8 shows the $\theta-2 \theta$ XRD spectrum obtained from the new AlN/Al/GaN/Sapphire stacking. The three AlN, GaN and materials show crystalline behavior, unlike Al IDTs which shows amorphous structure.

The sapphire substrate (stars) shows a clear (006) orientation of two peaks, the first close to $42^{\circ}$ is the $(006)$ orientation, the second, next to $91^{\circ}$ being the $(0012)$ orientation. An additional (024) orientation is visible. This could indicate some defect into the substrate, but the intensity of this (024) peak is small compared to the principle (006) orientation. Thus it does not affect our experiments.

The (002) expected orientation for the epitaxial $\mathrm{GaN}$ film is confirmed. This orientation can be observed through the (002) and (004) peaks, respectively located at $34.7^{\circ}$ and $73^{\circ}$. As for the sapphire substrate, the GaN layer can contain some defects illustrated by the weak (103) orientation close to $64.7^{\circ}$, which is not an issue in our case. 
The AlN thin film shows polycrystalline behavior. Most of AlN usual orientations are visible, which means that the deposed AlN won't show any monocrystallic behavior. Thus, the elastic constants of the experimental AlN won't fit the simulated constants. A difference of wave velocities between the simulated structure, and the experimental one is therefore expected. However, the AlN films shows a significant (002)-texture, by the (002) and (004) peaks respectively located at $36.2^{\circ}$ and $76.7^{\circ}$. This kind of structure is still interesting for the hoped oxygen diffusion barrier behavior.

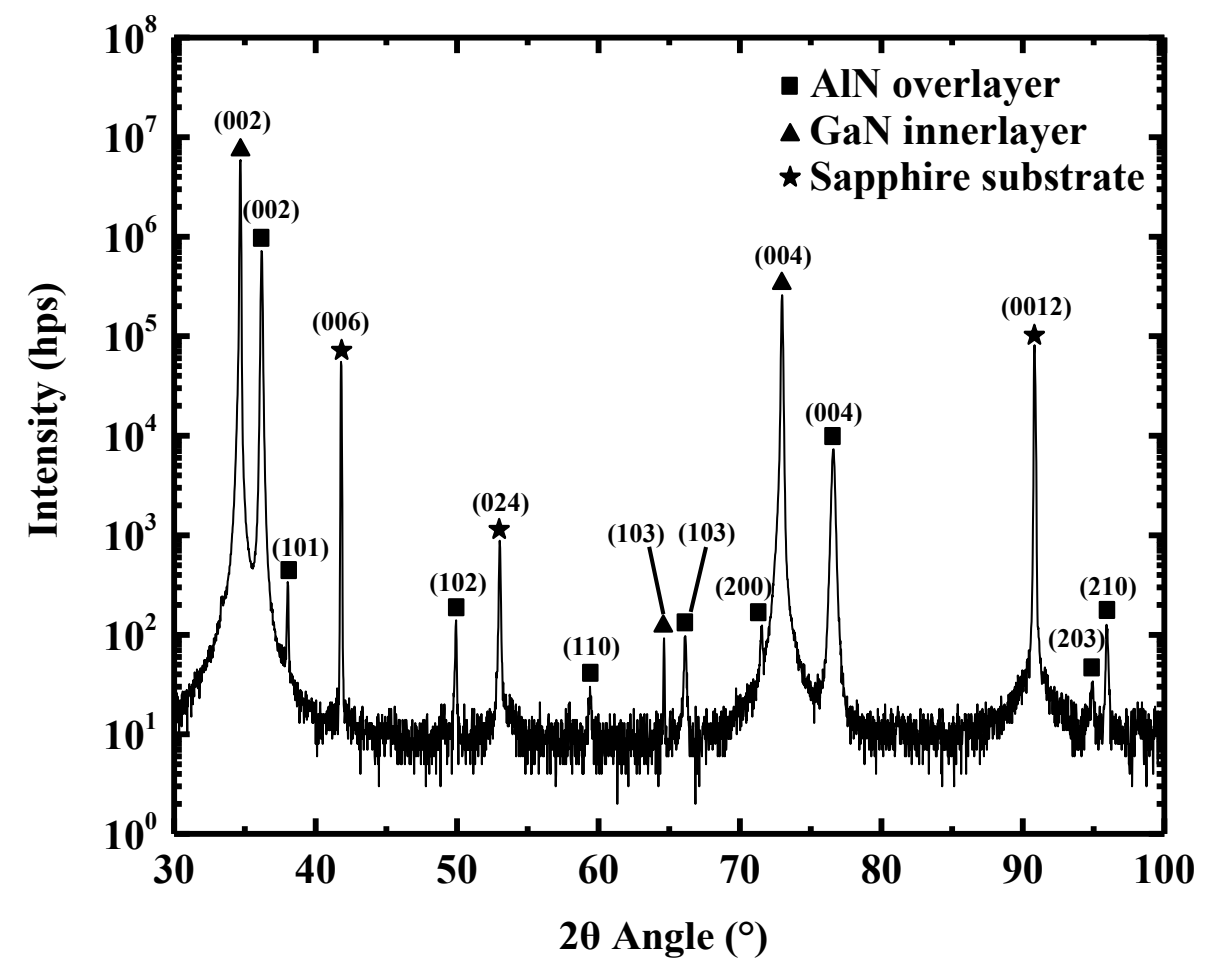

Fig. 8: $\theta-2 \theta$ XRD measurement of the AIN/Al/GaN/Sapphire device, where the thicknesses of GaN and AIN are respectively of $2 \mu \mathrm{m}$ and $12 \mu \mathrm{m}$.

Figures 9 shows the magnitude of the S11 scattering parameters measured on a GaN/Sapphire resonator with a wavelength of $5 \mu \mathrm{m}$ before and after the deposition of the $12 \mu \mathrm{m}$ thick AlN overlayer. Before deposition, the Rayleigh surface mode can be observed at 860 $\mathrm{MHz}$, which gives a wave velocity of $4300 \mathrm{~m} / \mathrm{s}$. That is in good agreement with the theoretically 
expected velocity $(4250 \mathrm{~m} / \mathrm{s})$. After deposition, the peak shifted towards $953 \mathrm{MHz}$, while the Q-factor strongly decreased to 30 from 600 . The corresponding phase velocity is close to 4800 $\mathrm{m} / \mathrm{s}$, in good agreement with the expected $5000 \mathrm{~m} / \mathrm{s}$ for the calculated WLAW mode.

The confined nature of this mode was finally experimentally confirmed by the specific test described in the experimental section: the $\mathrm{S}_{11}$ signal remains unchanged after the lamination of the soft Solaris elastomer onto the sample (Fig. 10).

The slight discrepancy of $200 \mathrm{~m} / \mathrm{s}$ between the experimental and the calculated velocity for this WLAW mode could come from the polycrystalline nature of the AlN film. We attribute the reduction in $\mathrm{Q}$ to both the decrease of the reflection coefficient of the resonator electrodes and to the dielectric loss in the AlN deposited over the electrodes. The former feature is common to devices in which the resonator is coated by different layers. In filters dense metal electrodes are used $(\mathrm{Cu})$ to oppose this phenomenon [33]. In high-temperature sensors, electrodes based on Pt and Ir are often the only choice [34] and can efficiently fit the purpose. For moderate temperature sensors with $\mathrm{Al}$ electrodes, the number of electrodes in reflecting gratings should be increased accordingly. So that this feature can be taken care-of with known methods. The latter feature is observed as a substantial increase in the electrical loss level. This effect manifests itself as a visible decrease of $\mathrm{S}_{11}$ (from about $-0.1 \mathrm{~dB}$ to about $-0.7 \mathrm{~dB}$ ) outside of the WLAW excitation region. We can attribute it to the dielectric loss in AlN deposited over the IDT electrodes. The damage of Al electrodes cannot be excluded either, but it seems less probable as the deposition temperature was not very high. Future development will have to take care of all of these effects.

The experimental $\mathrm{K}^{2}$ of the $\mathrm{Al} / \mathrm{GaN} / \mathrm{Sapphire} \mathrm{SAW}$ structure have been measured and is equal to $0.30 \%$, which is in agreement with the simulated $\mathrm{K}^{2}$, equal to $0.39 \%$. The deterioration of the signal after the AlN film deposition is too important to extract an accurate value of $\mathrm{K}^{2}$ for the WLAW structure. 


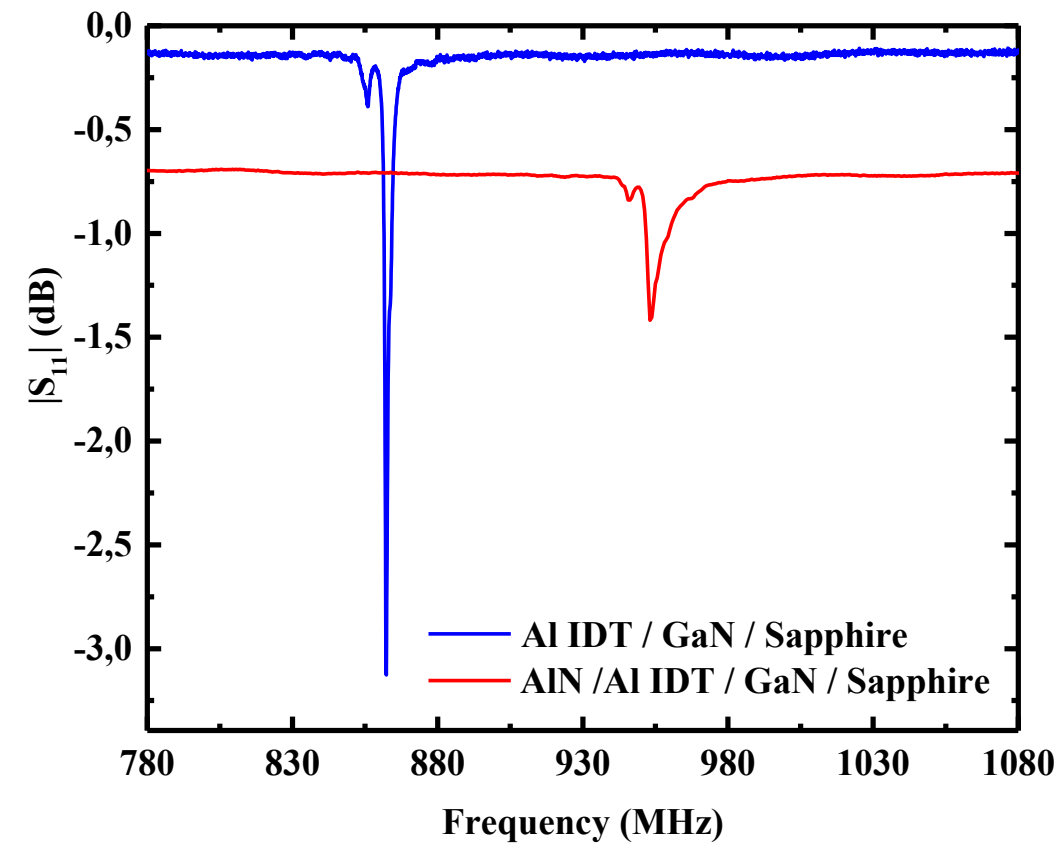

Fig. 9: Room-temperature $S_{11}$ magnitude of two resonators respectively based on the $\mathrm{Al} / \mathrm{GaN} / \mathrm{Sapphire}$ and the AIN/Al/GaN/Sapphire structures.

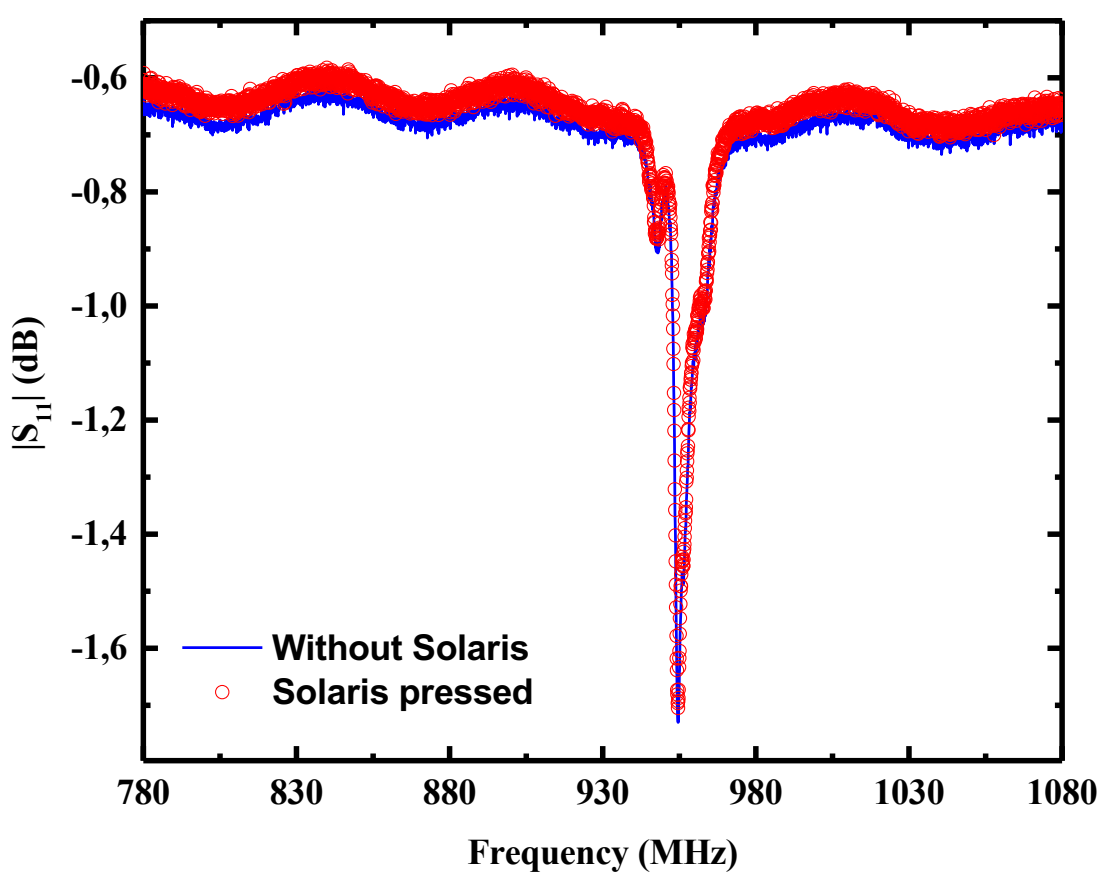

Fig. 10: Comparison of the $S_{11}$ magnitude of the AIN/Al/GaN/Sapphire WLAW device with and without the Solaris elastomer top layer. 


\subsection{High Temperature Results}

\subsubsection{AlN/Sapphire and GaN/Sapphire SAW devices}

All investigated SAW devices based on both AlN/Sapphire and GaN/Sapphire structures exhibit a quasi linear dependence of the operating frequency with the temperature up to $500^{\circ} \mathrm{C}$, independently from the film normalized thickness. In order to simulate the behavior of the SAW devices with the temperature, several sets of first-order temperature coefficients of elastic constants and thermal expansion coefficients were added to the model (see Table II).

Figure 11 shows the experimental and calculated dispersion of the TCF with the piezoelectric layer relative thickness for the AlN/Sapphire SAW structures. A good correlation is obtained for this structure when the AlN constant set from Ref. [26] are used. Thus, this set is considered as the most accurate and it is selected for the high-temperature study of the complete WLAW structure. The reliable constants coming from Ref. [20] are used for sapphire.

The same study was conducted regarding the GaN/Sapphire SAW devices. All the measured TCF values are reported on figure 12 and compared to the calculated ones. In that case, no set of GaN first-order temperature coefficients of elastic constants and thermal expansion coefficients leads to a good convergence in the full range of GaN normalized thicknesses considered here. Consequently, all the four GaN sets are considered in the subsequent simulation study of the AlN/Al/GaN/Sapphire WLAW device. 


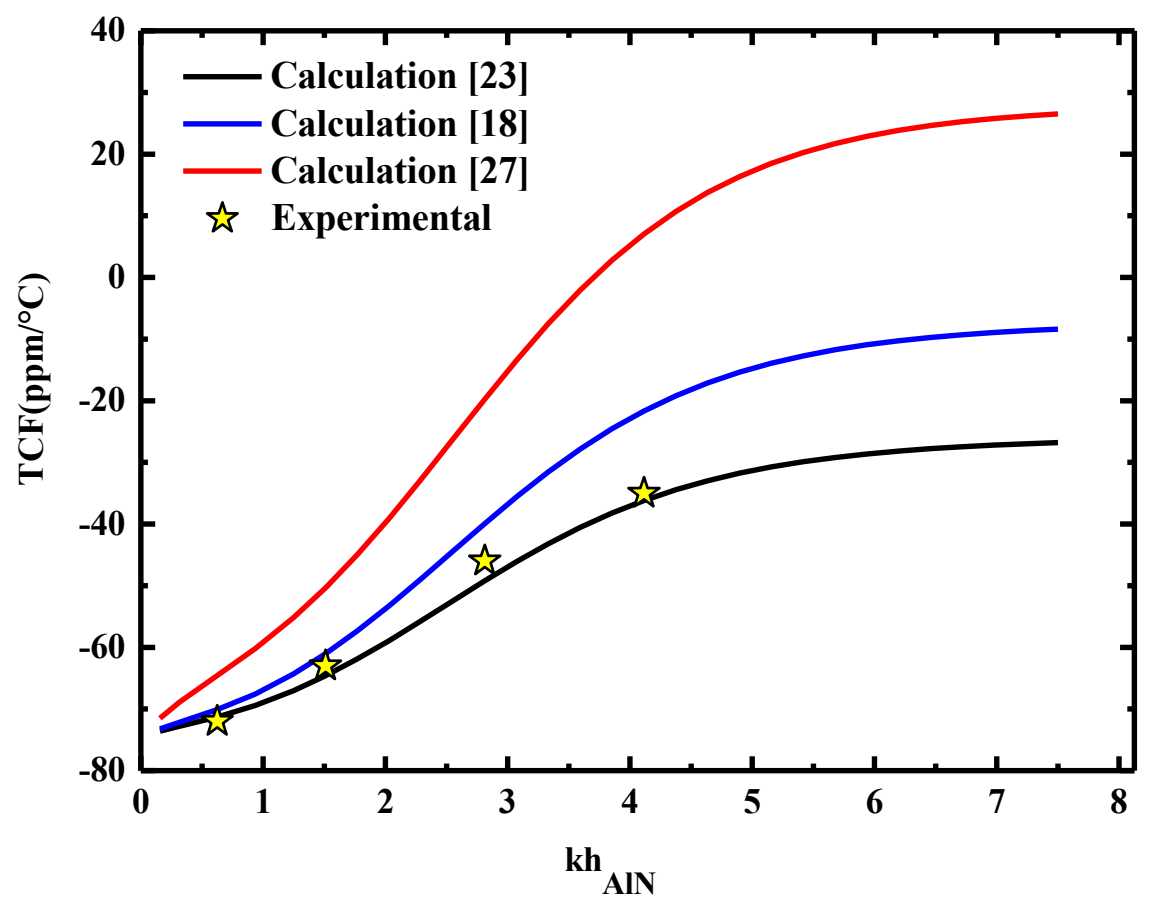

Fig. 11: Comparison between the experimental and calculated AIN/Sapphire TCF SAW dispersion curves.

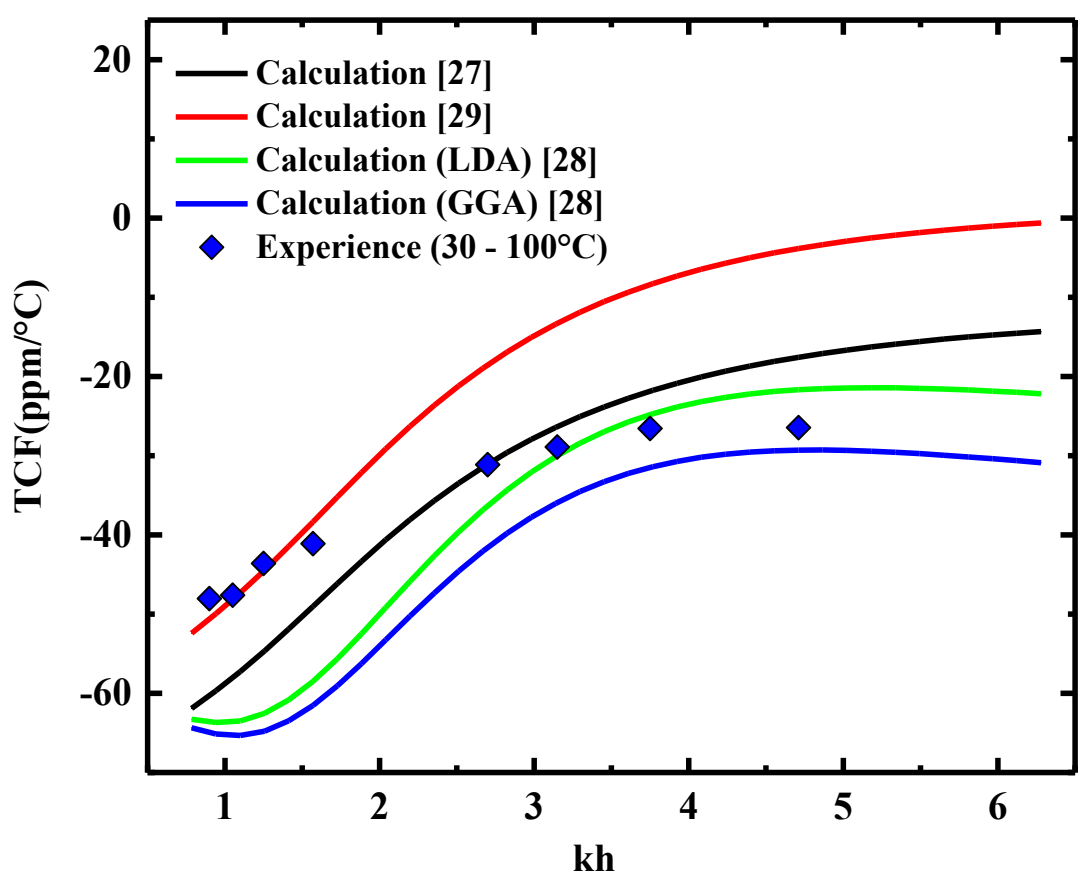

Fig. 12: Comparison between the experimental and calculated GaN/Sapphire TCF SAW dispersion curves. 


\subsubsection{AlN/Al/GaN/Sapphire WLAW device}

As for the GaN/Sapphire SAW devices, the complete WLAW device was electrically characterized between the ambient temperature and $500^{\circ} \mathrm{C}$. After cooling, the devices were characterized a second time in the same temperature range. The results are reproducible for both structures (Fig. 13). The WLAW device shows a linear frequency-temperature law, with a TCF value of $-34.6 \mathrm{ppm} /{ }^{\circ} \mathrm{C}$, corresponding to a slightly larger temperature sensitivity than the GaN/Sapphire SAW devices $\left(\mathrm{TCF}=-29.6 \mathrm{ppm} /{ }^{\circ} \mathrm{C}\right)$.

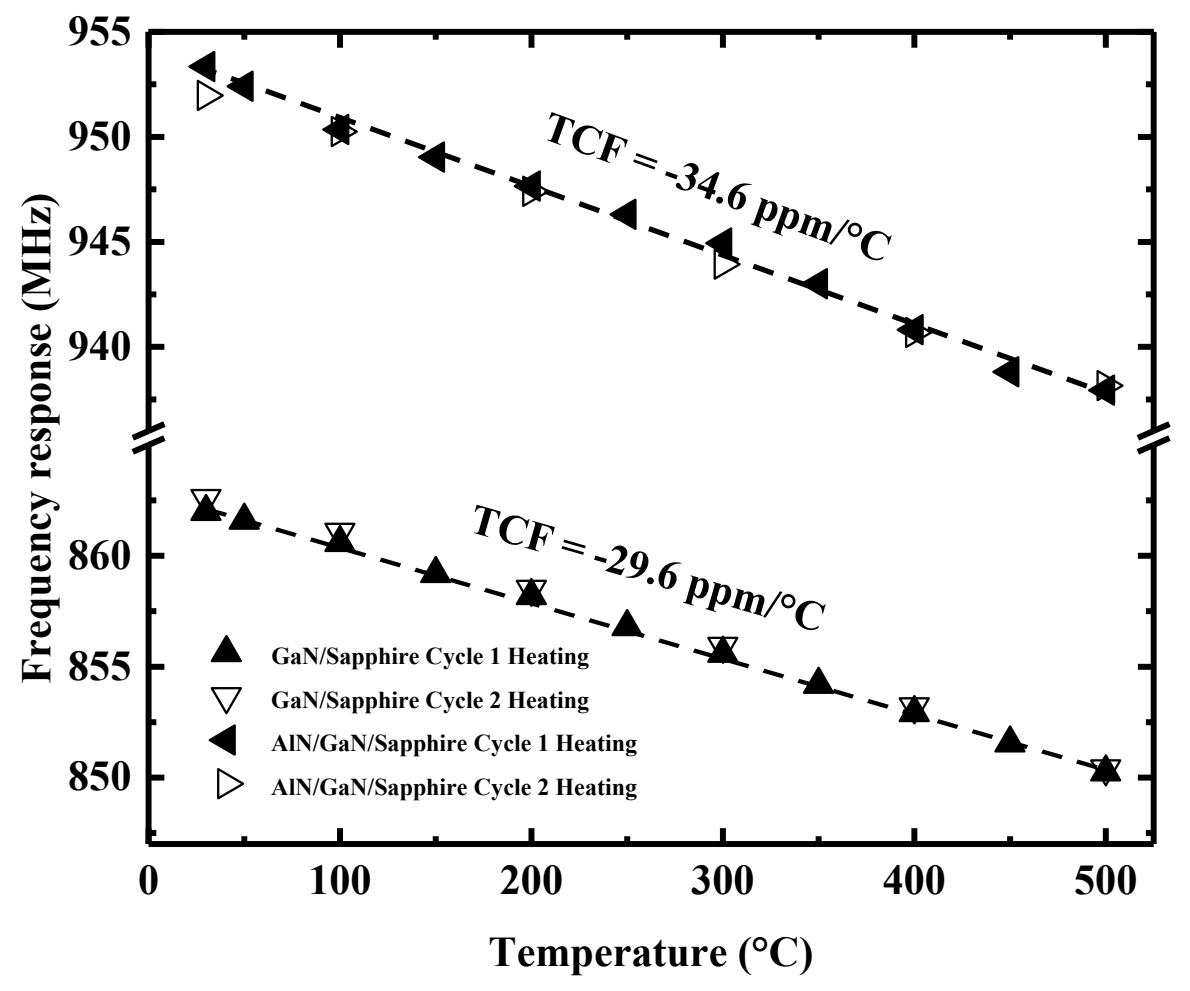

Fig. 13: Experimental frequency-temperature laws of the Al/GaN/Sapphire SAW device and the AIN/Al/GaN/Sapphire WLAW device.

Finally, the theoretical TCF of the AlN/Al/GaN/Sapphire WLAW structure was calculated using the coefficients coming from Ref. [20] for Sapphire, Ref [26] for AlN, and the four available data for GaN, as explained hereinabove (Tab. II). Calculated TCF values were equal to $-35 \mathrm{ppm} /{ }^{\circ} \mathrm{C},-30 \mathrm{ppm} /{ }^{\circ} \mathrm{C},-19 \mathrm{ppm} /{ }^{\circ} \mathrm{C}$, and $-17 \mathrm{ppm} /{ }^{\circ} \mathrm{C}$ with the $\mathrm{GaN}$ constant sets coming 
from references [27-GGA], [27-LDA], [27], and [29] respectively. The better agreement is obtained with sets from Ref. [27-GGA] and [27-LDA], which were also those giving the most accurate predictions concerning the TCF values of GaN/Sapphire SAW devices with large values of $\mathrm{GaN}$ relative thickness $(\mathrm{kh} \geq 3)$, i.e. those in which the acoustic wave is mostly located in the GaN film, which is one of the feature the WLAW mode.

\section{CONCLUSION}

The suitability of the WLAW AlN/Al/GaN/Sapphire structure for the future achievement of high-temperature packageless sensors has been evidenced in this study. Simulations based on reliable room-temperature constant sets of $\mathrm{AlN}, \mathrm{GaN}$ and sapphire materials show that a WLAW mode can be generated in this structure under certain conditions. Based on these calculations, an experimental device has been performed and characterized, confirming the possibility to excite a WLAW mode in the AlN/A1/GaN/Sapphire structure. Future developments will be focused on the improvement of the resonator device Q-factor which remains currently too weak, likely because of inadequate reflectors design and dielectric losses in the AlN film.

The behavior and the stability of the WLAW device was in situ investigated at temperatures up to $500^{\circ} \mathrm{C}$ with success. The frequency-temperature law appears to be linear and the temperature sensitivity is large, with a TCF value of $-34.6 \mathrm{ppm}$. This value can be retrieved by simulations means using first-order temperature coefficients of material constant sets for AlN, GaN and sapphire, whose robustness has been checked by basic SAW measurements. 


\section{REFERENCES}

[1] D. S. Ballantine, R. M. White, S. J. Martin, A. J. Ricco, E. T. Zellers, G. C. Frye, and H. Wohltjen; Acoustic Wave Sensors; R. Stern and M. Levy Academic, San Diego, CA, 1997.

[2] J. Hornsteiner, E. Born, G. Fischerauer and E. Riha. Surface acoustic wave sensors for hightemperature applications. Proceedings of the 1998 IEEE International Frequency Control Symposium, pp. 615 - 620, 1998. 10.1109/FREQ.1998.717964.

[3] T. Aubert and O. Elmazria. Stability of langasite regarding $S A W$ applications above $800^{\circ} \mathrm{C}$ in air atmosphere. Ultrasonics Symposium (IUS), 2012 IEEE International, pp. 2098 - 2101. 10.1109/ULTSYM.2012.0524.

[4] M. P. Da Cunha, A. Maskay, R. J. Lad, D. J. Frankel, S. Moulzolf, M. Call and G. Bernhardt. Pt-Ni / Pt-Zr electrodes for stable SAW resonator operation during repeated temperature cycling up to $1000^{\circ} \mathrm{C}$. 2015 IEEE International Ultrasonics Symposium (IUS), pp. 1 - 4. 10.1109/ULTSYM.2015.0028.

[5] P. Nicolay and T. Aubert. A Numerical Method to Derive Accurate Temperature Coefficients of Material Constants from High-Temperature SAW Measurements: Application to Langasite. IEEE Transactions on Ultrasonics, Ferroelectrics, and Frequency Control, Vol. 60, Issue 10, pp. 2137 - 2141, 2013. 10.1109/TUFFC.2013.2804.

[6] M. P. Da Cunha. Wireless Sensing in Hostile Environments. 2013 IEEE International Ultrasonics Symposium (IUS), pp. 1337 - 1346, 2013. 10.1109/ULTSYM.2013.0342.

[7] B. François, D. Richter, H. Fritze, Z. J. Davis, C. Droit, B. Guichardaz, V. Pétrini, G. Martin, J.-M. Friedt and S. Ballandras. Wireless and Passive Sensors for High Temperature Measurements. SENSORDEVICES 2012 The Third International Conference on Sensor Device Technologies and Applications, pp. 46- 51, 2012.

[8] H. Takeda, J. Yamaura, T. Hoshina and T. Tsusrumi. Structure and electrical properties of aluminum substituted langasite family crystals. IOP Conference Series: Materials Science and Engineering, Vol.18, Symposium 6, 2011. 10.1088/1757-899X/18/9/092020.

[9] T. Kim, J. Kim, R. Dalmau, R. Schlesser, E. Preble and X. Jiang. High-Temperature Electromechanical Characterization of AlN Single Crystals. IEEE Transactions on Ultrasonics, Ferroelectrics, and Frequency Control, Vol. 62, Issue 10, 2015. 10.1109/TUFFC.2015.007252. 
[10] T. Aubert, O. Elmazria, B. Assouar, A. Hamdan and D. Genève. Reliability of AlN/Sapphire bilayer structure for high-temperature SAW applications. Ultrasonics Symposium (IUS), 2010 IEEE, pp. 1490 - 1493. 10.1109/ULTSYM.2010.5935568.

[11] T. Aubert, J. Bardong, O. Legrani, O. Elmazria, M. B. Assouar and G. Bruckner. In situ high-temperature characterization of AlN-based surface acoustic waves devices. Journal of Applied Physics, Vol. 114, art. Nu 014505, 2013. 10.1063/1.4812565.

[12] C. Caliendo and P. M. Latino; Characterization of Pt/AlN/Pt-based structures for high temperature, microwave electroacoustic devices applications; Thin Solid Films 519 (2011) 6326-6329.

[13] B. François, J. M. Friedt, G. Martina and S. Ballandras. High temperature packaging for surface acoustic wave transducers acting as passive wireless sensors. Sensors and Actuators A: Physical, Vol. 224, pp. 6 - 13, 2015. 10.1016/j.sna.2014.12.034.

[14] K. Bhattacharjee, A. Shvetsov and S. Zhgoon. Packageless SAW Devices with Isolated Layer Acoustic Waves (ILAW) and Waveguiding Layer Acoustic Waves (WLAW). IEEE International Frequency Control Symposium, 2007, Joint with the 21st European Frequency and Time Forum. pp. 135-140. 10.1109/FREQ.2007.4319049.

[15] O. Legrani, O. Elmazria, S. Zhgoon, P. Pigeat and A. Bartasyte, "Packageless AlN/ZnO/Si Structure for SAW Devices Applications," IEEE Sensors Journal, vol. 13, no. 2, pp. 487-491, 2013.

[16] O. Legrani, T. Aubert, O. Elmazria, A. Bartasyte, P. Nicolay, A. Talbi, P. Boulet, J. Ghanbaja and D. Mangin. AlN/IDT/AIN/Sapphire SAW Heterostructure for High-Temperature Applications. IEEE Transactions on Ultrasonics, Ferroelectrics, and Frequency Control, Vol. 63, Issue 6, pp 898 - 906, 2016. 10.1109/TUFFC.2016.2547188.

[17] Y. Wei, Y. Gao, Z. Xiao, G. Wang, M. Tian and H. Liang. Ultrasonic Al2O3 Ceramic Thermometry in High-Temperature Oxidation Environment. Sensors, 16(11), pp. 1905, 2016. $10.3390 / \mathrm{s} 16111905$.

[18] O. Ambacher, M. S. Brandt, R. Dimitrov, T. Metzger, M. Stutzmann, R. A. Fischer, A. Miehr, A. Bergmaier and G. Dollinger. Thermal stability and desorption of Group III nitrides prepared by metal organic chemical vapor deposition. Journal of Vacuum Science \& Technology B, Nanotechnology and Microelectronics: Materials, Processing, Measurement, and Phenomena, Vol. 14, Issue 6, 1996. 10.1116/1.588793.

[19] J. Justice, K. Lee and D. Korakakis. Harmonic Surface Acoustic Waves on Gallium Nitride Thin Films. IEEE Transactions on Ultrasonics, Ferroelectrics, and Frequency Control, Vol. 59, Issue 8, 2012. 10.1109/TUFFC.2012.2385. 
[20] K. Tsubouchi and N. Mikoshiba. Zero-Temperature-Coefficient SAW Devices on AlN Epitaxial Films. IEEE Trans. on Sonics and Ultrasonics, Vol. SU-32, No. 5, pp. 634-644, 1985. 10.1109/T-SU.1985.31647.

[21] O. Elmazria, V. Mortet, M. El Hakiki, M. Nesladek and P. Alnot. High Velocity SAW Using Aluminum Nitride Film on Unpolished Nucleation Side of Free-Standing CVD Diamond. IEEE Transactions on Ultrasonics, Ferroelectrics, and Frequency Control, Vol. 50, Issue 6, pp. 710 715, 2003. 10.1109/TUFFC.2003.1209558.

[22] T. Aubert, O. Elmazria, B. Assouar, E. Blampain, A. Hamdan, D. Genève and S. Weber. Investigations on AlN/Sapphire Piezoelectric Bilayer Structure for High-Temperature SAW Applications. IEEE Transactions on Ultrasonics, Ferroelectrics, and Frequency Control, Vol. 59, Issue 5, pp 999 - 1005, 2012. 10.1109/TUFFC.2012.2285.

[23] E. Blampain, O. Elmazria, T. Aubert, B. Assouar and O. Legrani. AlN/Sapphire: a promising structure for high temperature and high frequency $S A W$ devices. IEEE Sensors Journal, Vol. 13, art. no. 6553003, pp. 4607 - 4612, 2013. 10.1109/JSEN.2013.2271863.

[24] E. Blampain, O. Elmazria, O. Legrani, S. Mc Murtry, F. Montaigne, C. Fu, K.K. Lee, and S.S. Yang. Pt/AlN/Sapphire SAW resonator operating in $\mathrm{GHz}$ range for High température Wireless SAW sensor. Proceedings of 2013 IEEE Intern. Ultrasonics Symposium, pp 10811084, 2013. 10.1109/ULTSYM.2013.0277.

[25] J. Vallin, M. Mongy, K. Salama, and O. Beckman; Elastic Constants of Aluminum; Journal of Applied Physics 35, 1825 (1964).

[26] J. Bjurström, G.Wingqvist, V. Yantchev and I. Katardjiev. Temperature compensation of liquid FBAR sensors. J. Micromech. Microeng, 17, pp. 651-658, 2007. 10.1088/0960$1317 / 17 / 3 / 030$.

[27] K. Adachi, H. Ogi, A. Nagakubo, N. Nakamura, M. Hirao, M. Imade, M. Yoshimura, and Y. Mori. Elastic constants of GaN between 10 and $305 \mathrm{~K}$. Journal of Applied Physics, 119, 245111, 2016. 10.1063/1.4955046.

[28] R. Reeber and K.Wang. High Temperature Elastic Constant Prediction of Some Group III-Nitrides. MRS Internet J. Semicond. Res. 6, 3, 2001. 10.1557/S1092578300000156.

[29] Y. Dai, S. Li, H. Gao, W. Wang, Q. Sun, Q. Peng, C. Gui, Z. Qian and S. Liu. Stress evolution in AlN and GaN grown on Si(111): experiments and theoretical modeling. Journal of Materials Science: Materials in Electronics, Vol. 27, Issue 2, pp. 2004-2013, 2016. 10.1007/s10854-015-3984-1. 
[30] C. Floer, M. Moutaouekkil, F. Bartoli, H. Mishra, S. Hage-Ali, S. Mc Murtry, P. Pigeat, O. Elmazria, T. Aubert, S. Zhgoon, O. Bou Matar, A. Talbi. AlN/ZnO/LiNbO3 packageless structure as a low-profile sensor for on-body applications. 2017 IEEE International Ultrasonics Symposium (IUS), pp. 1 - 4. 10.1109/ULTSYM.2017.8091766.

[31] J. Erhart, P. Pulpan and M. Pustka; Piezoelectric ceramic resonators; Book, Topics in mining, metallurgy and materials engineering, (2017).

[32] P. Varshney, B. S. Panwar, P. Rathore, S. Ballandras, B. Francois, G. Martin, J. M. Friedt and T. Rétornaz; Theoretical and experimental analysis of high $Q S A W$ resonator transient response in wireless sensor interrogation application; IEEE Frequency control symposium, (2012).

[33] B. Abbott, A. Chen, T. Daniel, K. Gamble, T. Kook, M. Solal, K. Steiner, R. Aigner, S. Malocha, C. Hella, M. Gallagher and J. Kuypers. Temperature compensated saw with high quality factor. 2017 IEEE International Ultrasonics Symposium (IUS), pp. 1 - 7. 10.1109/ULTSYM.2017.8092294.

[34] A. Taguett, T. Aubert, M. Lomello, O. Legrani, O. Elmazria, J. Ghanbaja and A. Talbi. Ir$R h$ thin films as high-temperature electrodes for surface acoustic wave sensor applications 2016. Sensors and Actuators A: Physical, Vol. 243, pp. 35-42, 2016. 10.1016/j.sna.2016.03.008. 